\title{
Aeromonas punctata derived depolymerase improves susceptibility of Klebsiella pneumoniae biofilm to gentamicin
}

\author{
Shruti Bansal, Kusum Harjai and Sanjay Chhibber ${ }^{*}$
}

\begin{abstract}
Background: To overcome antibiotic resistance in biofilms, enzymes aimed at biofilm dispersal are under investigation. In the present study, applicability of an Aeromonas punctata derived depolymerase capable of degrading the capsular polysaccharide (CPS) of Klebsiella pneumoniae, in disrupting its biofilm and increasing gentamicin efficacy against biofilm was investigated.

Results: Intact biofilm of K. pneumoniae was recalcitrant to gentamicin due to lack of antibiotic penetration. On the other hand, gentamicin could not act on disrupted biofilm cells due to their presence in clusters. However, when depolymerase (20 units $/ \mathrm{ml})$ was used in combination with gentamicin $(10 \mu \mathrm{g} / \mathrm{ml})$, dispersal of CPS matrix by enzyme facilitated gentamicin penetration across biofilm. This resulted in significant reduction $(p<0.05)$ in bacterial count in intact and disrupted biofilms. Reduction in CPS after treatment with depolymerase was confirmed by confocal microscopy and enzyme linked lectinosorbent assay. Furthermore, to substantiate our study, the efficacy of bacterial depolymerase was compared with a phage borne depolymerase possessing similar application against $K$. pneumoniae. Although both were used at same concentration i.e. 20 units $/ \mathrm{ml}$, but a higher efficacy of bacterial depolymerase particularly against older biofilms was visibly clear over its phage counterpart. This could be explained due to high substrate affinity (indicated by $K_{m}$ value) and high turnover number (indicated by $K_{c a t}$ value) of the bacterial depolymerase $\left(K_{m}=89.88 \mu \mathrm{M}, K_{c a t}=285 s^{-1}\right)$ over the phage derived one $\left(K_{m}=150 \mu M, K_{c a t}=107 s^{-1}\right)$.

Conclusion: Overall the study indicated that, the A. punctata derived depolymerase possesses antibiofilm potential and improves gentamicin efficacy against K. pneumoniae. Moreover, it can serve as a potential substitute to phage borne depolymerases for treating biofilms formed by K. pneumoniae.
\end{abstract}

Keywords: Anti-biofilm enzyme, Bacterial depolymerase, Phage depolymerase, Enzyme kinetics, Gentamicin

\section{Background}

Biofilm is a community of microorganisms embedded in a self produced polymeric matrix comprising of polysaccharides, proteins, glycopeptides, nucleic acids and lipids [1]. Currently, it is estimated that over $60 \%$ of bacterial infections and up to $80 \%$ of chronic infections involve microbial growth in biofilms [2]. K. pneumoniae is frequently encountered in hospital-acquired urinary tract infections (UTI), respiratory illnesses, burn wound infections, surgical site and catheter-related infections [3]. Mortality rates due to infections by this organism range

\footnotetext{
* Correspondence: sanjaychhibber8@gmail.com

Department of Microbiology, Panjab University, Sector-14, Chandigarh 160014, India
}

(c) 2015 Bansal et al. This is an Open Access article distributed under the terms of the Creative Commons Attribution License (http://creativecommons.org/licenses/by/4.0), which permits unrestricted use, distribution, and reproduction in any medium, provided the original work is properly credited. The Creative Commons Public Domain Dedication waiver (http:// creativecommons.org/publicdomain/zero/1.0/) applies to the data made available in this article, unless otherwise stated.
$25-60 \%[4,5]$. Biofilm formation is a major virulence trait used by $K$. pneumoniae to colonize the human host [6]. The acidic CPS encasing the bacterium provides resistance against dessication, phagocytosis, killing by serum, induces cytotoxicity during infection of lung epithelial cells and helps in biofilm formation at the infection site [7, 8]. Recently, hypermucoviscous variants of $K$. pneumoniae with increased virulence have emerged in the Asia Pacific region and they are spreading across the globe [9]. This dense, sticky mix of negatively charged polysaccharides forms a three dimensional scaffold which can range in thickness upto $50 \mu \mathrm{m}[10,11]$. It retards or blocks the penetration of antibiotics particularly positively charged aminoglycosides, thus restricting their access to the deeper layers [12]. This leads to sub-optimal 
levels of antibiotics reaching bacterial cells embedded in a biofilm. Exposure of bacteria to sub-MIC concentrations can further complicate the situation by enhancing CPS production and increasing the emergence of resistant strains. This has been observed in encapsulated isolates of K. pneumoniae, Escherichia coli, P. aeruginosa [13]. Multicellular nature of the polysaccharide also leads to creation of nutrient starved zones in the biofilm interior as a result of which some cells enter into a metabolically inactive state leading to inability of antibiotics to act on them [14]. Chemical disinfectants like nitric oxide, metal chelators like sodium citrate or tetrasodium-EDTA have been used to disrupt biofilms in healthcare and industrial settings but they leave toxic residues which have adverse effects [15]. To overcome drug resistance in biofilms, efforts are being directed towards developing anti-biofilm enzymes. Polysaccharide-degrading enzymes like $\alpha$-amylases, dispersin B (DspB), alginate lyases, deoxyribonucleases (DNAses), phage depolymerases have been successfully used for preventing biofilm formation or disrupting the biofilms of S. aureus, S. epidermidis, E. coli and P. aeruginosa, K. pneumoniae [16]. Such enzymes offer several advantages: firstly, they are safe and have no side effects. Secondly, they do not require actively growing cells for their action and can act with the same frequency on metabolically active as well as inert cells [17, 18]. Thirdly, they are not directly bactericidal so they do not allow generation of resistant mutants. Although, the potential of phage depolymerases for disrupting the biofilms of $K$. pneumoniae and mediating the entry of antimicrobials has been recognized but, no report is available describing the use of enzymes from unrelated bacterial genera for disrupting $K$. pneumoniae polysaccharide in biofilms. The present study was undertaken to study the potential of a Aeromonas punctata derived depolymerase directed against K2 CPS of K. pneumoniae in disrupting the biofilms formed by this pathogen and improving its susceptibility to antibiotic. The biofilm disruption efficacy of $A$. punctata derived depolymerase with a previously characterized phage borne depolymerase against $K$. pneumoniae B5055 was also compared.

\section{Methods}

\section{Bacterial strain, antibiotic}

K. pneumoniae B5055 (O1:K2) [MTCC 5832] obtained from Dr. M. Trautman, Department of Medical Microbiology and Hygiene, University of Ulm, Germany was used in the present study. Maintenance of bacteria on nutrient agar slants and preparation of gentamicin (Himedia, India) was done as described previously [19]. Gentamicin was used at a final concentration of $10 \mu \mathrm{g} /$ $\mathrm{ml}$ throughout the study.

\section{Enzyme}

Aeromonas punctata (Accession no: KF158411) was cultivated in a statistically optimized media as standardized in our laboratory [20]. Cell free supernatant containing bacterial depolymerase directed against K2 CPS of $K$. pneumoniae B5055 was obtained. The enzyme was purified by anion exchange (DEAE) followed by gel filtration chromatography (Sephadex G100) [20]. CPS extracted from K. pneumoniae B5055 following the method of Hanlon et al. [21] was used as substrate for determining depolymerase activity by the method of Miller [22]. One unit of enzyme activity was defined as the micromoles of reducing sugars released $\mathrm{ml}^{-1} \mathrm{~min}^{-1}$ when the reaction was carried out at $37{ }^{\circ} \mathrm{C}$ and $\mathrm{pH} 7$ for $60 \mathrm{~min}$. Temperature and $\mathrm{pH}$ optima and stability for bacterial depolymerase are depicted in Additional file 1: Figure S1. Enzyme kinetics was determined for the purified protein using various substrate concentrations and $\mathrm{K}_{\mathrm{m}}, \mathrm{V}_{\text {max }}, \mathrm{k}_{\mathrm{cat}}, \mathrm{k}_{\mathrm{cat}} / \mathrm{K}_{\mathrm{m}}$ were calculated for the enzyme (Additional file 1: Figure S2).

For all experiments involving the use of A. punctata derived bacterial depolymerase for various applications, a previously characterized phage depolymerase capable of acting on K2 CPS of $K$. pneumoniae B5055 was also used. Phage depolymerase was extracted from a previously characterized, $K$. pneumoniae specific phage 'KPO1K2' (Verma et al. [23]) following the acid denaturation method of Reiger et al. [24]. Its purification and quantification was carried out in a similar manner as done for bacterial depolymerase. Both the enzymes were used at a concentration of 20 depolymerase units. All experiments involving the use of both the biological moieties were performed at $37{ }^{\circ} \mathrm{C}$ and $\mathrm{pH} 7$ which was the temperature and $\mathrm{pH}$ optima for both the enzymes. The characteristics of phage depolymerase are depicted in Additional file 1: Figure S3 and Table S1.

\section{Capsule staining}

Overnight culture of $K$. pneumoniae B5055 grown in nutrient broth at $37{ }^{\circ} \mathrm{C}$ was taken, cells were washed with PBS and diluted to obtain a count of $10^{6} \mathrm{CFU} / \mathrm{ml}$. Bacterial depolymerase was added to a final concentration of 20 units $/ \mathrm{ml}$ and cells were incubated for $30 \mathrm{~min}$ at $37^{\circ} \mathrm{C}$. Cells suspended in PBS acted as control. Both the bacterial suspensions were taken on a clean glass slides, mixed with a drop of safranin and a smear was made. It was then counterstained with crystal violet for $1 \mathrm{~min}$, washed and examined under a light microscope.

\section{Penetration of gentamicin through intact biofilm}

Penetration of gentamicin through biofilm formed by $K$. pneumoniae was determined according to the method of Anderl et al. [25] with modifications. Overnight culture of $K$. pneumoniae grown in nutrient broth was taken, cells were washed and diluted to obtain a bacterial count 
of $10^{8} \mathrm{CFU} / \mathrm{ml} .10 \mu \mathrm{l}$ of this bacterial culture was used to seed $25 \mathrm{~mm}$ polycarbonate discs $(0.4 \mu \mathrm{m}$, Millipore) placed on nutrient agar plates. The drop was allowed to dry and plates were incubated at $37^{\circ} \mathrm{C}$. On days $1,3,5$, 7, membrane biofilms were transferred to fresh nutrient agar plates containing a fresh lawn of $E$. coli ATCC 25922 (standard strain of $E$. coli used for quality control). On top of biofilm formed on $25 \mathrm{~mm}$ polycarbonate membrane, sterile $13 \mathrm{~mm}$ membrane $(0.4 \mu \mathrm{m}$, Millipore) was carefully placed, such that the underlying biofilm was not disturbed. Sterile gentamicin disc $(10 \mu \mathrm{g} / \mathrm{ml}$, Hi-media) was then gently kept on the top of it and plates were incubated at $37{ }^{\circ} \mathrm{C}$. Next day zone of clearance was measured on nutrient agar plate containing a lawn of E. coli ATCC 25922 [25]. Control assembly in which gentamicin disc was kept over sterile polycarbonate disc devoid of biofilm was also put alongwith the test. The zone of growth inhibition in control assembly was taken as $100 \%$ penetration and used for determining the percentage penetration/retardation of antibiotic through biofilm. Experiment was repeated thrice in triplicates.

\section{Antibiotic susceptibility of planktonic, intact and disrupted biofilm cells}

Intact biofilm was established in 96 well microtiter plate following the method described by Bedi et al. [26]. Briefly, $100 \mu \mathrm{l}$ of nutrient broth and $100 \mu \mathrm{l}$ of bacterial culture equivalent to $10^{8} \mathrm{CFU} / \mathrm{ml}\left(\mathrm{OD}_{600}=0.3\right)$ of $K$. pneumoniae was added to the wells and incubated overnight at $37{ }^{\circ} \mathrm{C}$. After $24 \mathrm{~h}$, supernatant was aspirated from the wells $(n=6)$ and 3 washings were given with sterile $0.85 \% \mathrm{NaCl}$. Thereafter, gentamicin $(10 \mu \mathrm{g} / \mathrm{ml})$ was added to wells $(n=6)$. Biofilm in wells $(n=3)$ was disrupted using sterile toothpick according to the method described by El-Azizi et al. [27]. After an incubation of $6 \mathrm{~h}$, wells with disrupted biofilm were aspirated $(n=3)$ while those with intact biofilm $(n=3)$ were scraped and added to sterile eppendorfs. The bacteria were vortexed and appropriately diluted in sterile $0.85 \%$ $\mathrm{NaCl}$. Bacterial count was estimated by plating the samples on nutrient agar plates. Percentage viability was calculated as ratio of cells in treated wells to cells in untreated, control wells multiplied by 100 . In addition, to determination of viable count, the intact and disrupted biofilm were viewed under a fluorescent microscope (B2A filter set, Nikon, $40 \mathrm{X}$ ) after staining with Live/Dead staining Kit (Invitrogen) for 15 min. [Live/ Dead staining kit contains 3.34 mM Syto 9 (stains live cells green) and $20 \mathrm{mM}$ Propidium iodide (stains dead cells red)].

Simultaneously, antibiotic susceptibility of planktonic cells was determined by growing bacteria in $1 \mathrm{ml}$ nutrient broth. After an incubation of $24 \mathrm{~h}$, bacterial suspension was centrifuged, washed twice with $0.85 \% \mathrm{NaCl}$ and suspended in $1 \mathrm{ml}$ fresh nutrient broth with gentamicin $(10 \mu \mathrm{g} / \mathrm{ml})$. After $6 \mathrm{~h}$ of incubation, bacteria were stained and percentage viability was determined by viable count.

\section{Treatment of intact and disrupted biofilm with depolymerase and antibiotic alone as well as in combination}

Biofilm was formed in microtiter titer plate as described in section Antibiotic susceptibility of planktonic, intact and disrupted biofilm cells. On each day, supernatant was aspirated from all the wells and replaced with fresh nutrient broth. Three washings were given with sterile $0.85 \% \mathrm{NaCl}$ to a certain number of wells $(n=30)$. They were treated with various agents [gentamicin $(10 \mu \mathrm{g} /$ $\mathrm{ml}$ )/phage depolymerase (20 units/ml)/bacterial depolymerase (20 units/ml)/gentamicin + phage depolymerase/ gentamicin + bacterial depolymerase, $n=6$ each]. Biofilm in certain number of wells $(n=15)$ was disrupted using sterile toothpick by the method of El-Azizi et al. [27]. After an incubation of $6 \mathrm{~h}$, wells with disrupted $(n=15)$ and intact biofilm $(n=15)$ were processed as described in section Antibiotic susceptibility of planktonic, intact and disrupted biofilm cells and viable count determined by plating the samples on nutrient agar plates. Biofilm was allowed to grow in different wells till 7 days. On each day, a set of 3 wells was processed for control, untreated intact and disrupted biofilm and the experiment was repeated thrice. The data was log transformed and for each time point mean of all replicate values was taken.

\section{Confocal laser-scanning microscopy (CLSM) of biofilm}

Sterile plastic cover slips $(18 \times 18 \mathrm{~mm})$ placed in 12 well mutidishes (Nunc) were inoculated with $1.5 \mathrm{ml}$ culture of $K$. pneumoniae $\left(1 \times 10^{8} \mathrm{CFU} / \mathrm{ml}\right)$ and $1.5 \mathrm{ml}$ nutrient broth and incubated at $37^{\circ} \mathrm{C}$. Each day, spent medium was removed and replaced with fresh nutrient broth. On $3^{\text {rd }}$ and $7^{\text {th }}$ day, the cover slips were washed thrice with $0.85 \% \mathrm{NaCl}$, followed by treatment with 20 units $/ \mathrm{ml}$ of either phage or bacterial depolymerase for $1 \mathrm{~h}$ at $37^{\circ} \mathrm{C}$. Thereafter, the cover slips with untreated and treated biofilms were stained with $300 \mathrm{mg} / \mathrm{ml}$ calcofluor white (Sigma) [calcofluor white binds to the sugar residues in the biofilm polysaccharide and stains them blue] and $0.1 \%$ Syto 62 (Molecular Probes) [Syto 62, a nucleic acid staining dye stains the bacterial cells red] for 15 min each. These were then examined under a Inverted Olympus Fluoview CLSM (FV 1000, Olympus America Inc. NY, USA). All images were obtained with a 20X lens. Multiple images were collected for each set of experimental conditions; a representative image is presented for each group in the results section. Image analysis was done using $\mathrm{z}$ series image stacks from four randomly chosen spots of each biofilm. The ratio of cell biomass to polysaccharide 
was calculated by dividing the integrated red fluorescence density with integrated blue fluorescence density using ImageJ version 1.46r [57].

\section{Quantitative estimation of CPS by enzyme linked lectinosorbent assay (ELLA)}

CPS was quantified in the untreated/treated biofilm following the method of Strathmann et al. [28]. Briefly, intact biofilm was grown in microtiter plate and appropriately treated with phage/bacterial depolymerase as described in section Treatment of intact and disrupted biofilm with depolymerase and antibiotic alone as well as in combination. The biofilm was subsequently washed with phosphate buffer saline (PBS, $0.1 \mathrm{M}, \mathrm{pH}$ 7.2) twice and fixed with $200 \mu \mathrm{l}$ of $95 \%$ ethanol for $15 \mathrm{~min} .100 \mu \mathrm{l}$ of blocking solution $[1 \% \mathrm{w} / \mathrm{v}$ BSA in PBST (PBS plus $0.05 \%$ Tween 20)] was added to the wells and incubated for $1 \mathrm{~h}$ at $37^{\circ} \mathrm{C}$. It was then pipetted out and $100 \mu \mathrm{l} \mathrm{ConA-HRP}(10 \mathrm{mg} /$ $\mathrm{ml}$ ) in $1 \%$ BSA in PBST was added to wells. The microtiter plate was incubated for $30 \mathrm{~min}$ at $37{ }^{\circ} \mathrm{C}$. Wells were washed thrice for 5 min with PBST. $100 \mu$ of TMB substrate (BD Biosciences) was added and microtiter plate was incubated for $30 \mathrm{~min}$ at $37{ }^{\circ} \mathrm{C}$. Reaction was stopped by adding $50 \mu \mathrm{l}$ of $2 \mathrm{~N} \mathrm{H}_{2} \mathrm{SO}_{4}$. CPS content $(\mu \mathrm{g} / \mathrm{ml})$ was measured in terms of peroxidase activity by taking absorbance at $450 \mathrm{~nm}$. Experiment was performed in triplicate and repeated thrice.

\section{Statistical analysis}

The effect of different treatments on biofilm was evaluated by applying one-way ANOVA and $P<0.05$ was considered significant. Data was analyzed using SPSS 16.0.

\section{Results}

The present study was conducted to evaluate the potential of A. punctata derived depolymerase to decapsulate K. pneumoniae B5055 and improve gentamicin efficacy against its biofilms.

\section{Enzyme kinetics for bacterial depolymerase}

Bacterial depolymerase exhibited simple hyperbolic Michaelis-Menten kinetics. Lineweaver Burk plot was constructed and values depicting its kinetics i.e. $\mathrm{K}_{\mathrm{m}}$, $\mathrm{V}_{\max }, \mathrm{k}_{\mathrm{cat}}$ and $\mathrm{k}_{\mathrm{cat}} / \mathrm{K}_{\mathrm{m}}$ were calculated as $89.88 \mu \mathrm{M}$, $43.35 \mu \mathrm{mol} \mathrm{min}{ }^{-1}, 285 \mathrm{~s}^{-1}$ and $3.17 \mathrm{~s}^{-1} \cdot \mu \mathrm{M}^{-1}$ respectively (Additional file 1: Figure S2). Enzyme kinetics was also determined for the phage depolymerase and the values for $\mathrm{K}_{\mathrm{m}}$,

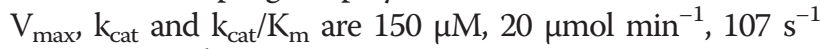
and $0.71 \mu \mathrm{M}^{-1}$ respectively. (Additional file 1: Table S1).

\section{Microscopic examination of bacteria after capsule staining}

A clear hollow depicting capsule was visible surrounding the untreated bacteria (Fig. 1a). On the other hand, depolymerase treated bacteria were devoid of any capsule (Fig. 1b).

\section{Penetration of gentamicin}

Percentage retardation of gentamicin through colony biofilm of K. pneumoniae established on $25 \mathrm{~mm}$ polycarbonate disc was studied. As shown in Table 1, in comparison to inhibition zone observed on plates having membrane with no biofilm, a significant decrease in the diameter of inhibition zone $(p<0.05)$ was observed on plates in which membrane with colony biofilm was placed. Percentage antibiotic retardation increased with an increase in biofilm age. Retardation of gentamicin was $26.66 \%$ for 1 day old biofilm. It progressively increased to $86.66 \%$ for 7 day old biofilm (Table 1).

\section{Antibiotic susceptibility of planktonic, intact and disrupted biofilm cells}

Percentage viability of planktonic cells, intact and disrupted biofilm cells treated with gentamicin was $10 \%$, $100 \%$ and $99.6 \%$ respectively. Visualization of gentamicin treated cells under a fluorescent microscope indicated resistance of intact biofilm as a great number of green coloured viable cells (Syto 9 stained; Fig. 2b) were observed. The disrupted biofilm also consisted of large clumps of mostly viable, green cells (Fig. 2c). In contrast, all planktonic cells were dead as they acquired red color (PI stained, Fig. 2a). This indicated that, the disrupted biofilm cells were more or less similar in their antibiotic susceptibility pattern to bacteria in a intact biofilm.

\section{Effect of depolymerase and antibiotic alone as well as in combination on intact biofilm}

The efficacy of depolymerase on gentamicin penetration and bacterial count was studied in intact biofilm. No significant difference $(p>0.05)$ was observed in average bacterial count of gentamicin treated biofilm and untreated biofilm (Fig. 3). This indicated the inability of antibiotic alone to tackle biofilm. When bacterial depolymerase was used alone, an average reduction of $3.261 \pm$ $0.14 \log$ in bacterial count was observed in comparison to untreated biofilm (Fig. 3). In contrast, an average reduction of $2.242 \pm 0.21 \mathrm{log}$ was observed after treatment with phage depolymerase alone (Fig. 3). Treatment with gentamicin and phage or bacterial depolymerase resulted in significant reduction $(p<0.05)$ of $4.259 \pm 0.34 \log$ and $5.373 \pm 0.18 \mathrm{log}$ respectively in bacterial counts of young biofilm (till $4^{\text {th }}$ day) (Fig. 3). $5^{\text {th }}$ day onwards a significant reduction of $3.506 \pm 0.16 \log (p<0.05)$ was observed in biofilm treated with bacterial depolymerase and gentamicin. In contrast, an insignificant reduction $(p>0.05)$ was observed in biofilm treated with phage depolymerase and gentamicin (Fig. 3). 

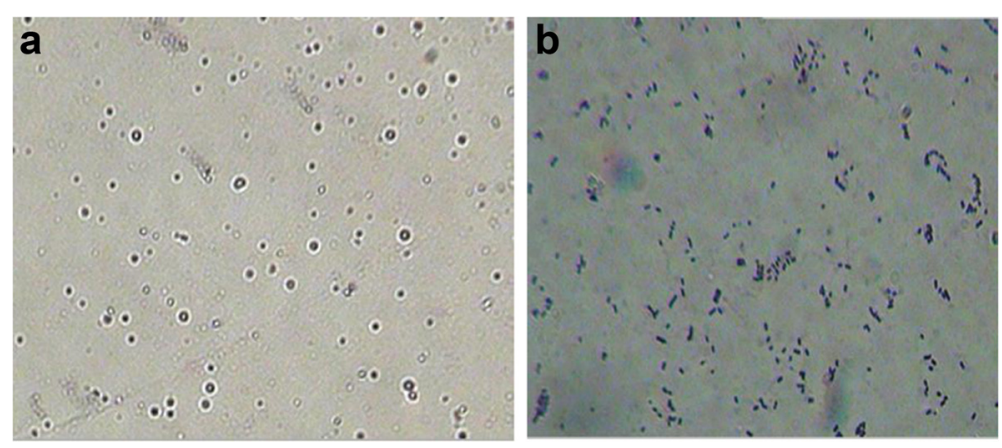

Fig. 1 Microscopic appearance of K. pneumoniae B5055: (a) encapsulated untreated bacteria (b) depolymerase treated bacteria

\section{Effect of depolymerase and antibiotic alone as well as in combination on disrupted biofilm}

No significant difference $(p>0.05)$ was observed in average bacterial count of gentamicin treated and untreated disrupted biofilm (Fig. 4). Therefore, disrupted biofilm was treated with phage/bacterial depolymerase alone as well as in combination with gentamicin. In comparison to untreated biofilm, no significant reduction $(p>0.05)$ was observed in the count of disrupted cells (Fig. 4) after treatment with phage or bacterial depolymerase alone. However, on negative staining, bacteria were found to be devoid of capsule compared to untreated cells (data not presented). Treatment with either of the enzyme in combination with gentamicin resulted in complete eradication of 1 day old biofilm (Fig. 4). $2^{\text {nd }}$ day onwards a significant reduction $(p<0.05)$ of $6.679 \pm 0.21 \log$ in the average bacterial count was observed after treatment with bacterial depolymerase and gentamicin. In contrast, an average reduction of $5.121 \pm 0.18 \log$ was observed in biofilm treated with phage depolymerase and gentamicin in combination (Fig. 4).

\section{Qualitative analysis of CPS in biofilm}

To determine the ability of bacterial depolymerase in dispersing the polysaccharide matrix enmeshing the bacterial cells, untreated/treated biofilms were visualized under a confocal microscope. Cover slips with biofilm treated with phage depolymerase were also put up simultaneously. In images taken using CLSM, blue regions represent polysaccharide matrix while red regions indicate zones containing cells of $K$. pneumoniae (Fig. 5). Purple regions resulted from overlap of red and blue pixels; representing bacterial cells embedded in polysaccharide. With an increase in biofilm age, an increase in biofilm bacterial mass (red) as well as dense matrix (blue) was observed in untreated biofilm (Fig. 5a and b). This indicated high bacterial density and tightly packed regions of heterogeneously distributed dense polysaccharide in the form of tower or mushroom-shaped clusters in untreated biofilm. A significant change was observed in the enzyme treated biofilm. In comparison to young biofilm treated with phage depolymerase (Fig. 5c), biofilm treated with bacterial depolymerase showed significant decrease in polysaccharide matrix (indicated by blue regions) as well as in surface coverage by bacterial cells (indicated by red regions) (Fig. 5e). In young biofilms, ratio of cell biomass to polysaccharide matrix (integrated red fluorescence density/ integrated blue fluorescence density) after bacterial depolymerase treatment was $2.95 \mathrm{U}$ whereas after phage depolymerase treatment it was $1.14 \mathrm{U}$. In phage depolymerase treated old biofilm, polysaccharide was sparsely distributed in certain areas (Fig. 5d) whereas in bacterial depolymerase treated old biofilm cloud like structure of polysaccharide was rarely present (Fig. 5f). Ratio of cell biomass to polysaccharide in 7 day old biofilm treated with bacterial depolymerase $(1.51 \mathrm{U})$ was significantly higher $(p<0.01)$ than that observed after phage depolymerase treatment $(0.58 \mathrm{U})$ or in untreated biofilm $(0.34 \mathrm{U})$. No significant

Table 1 Penetration of gentamicin $(10 \mu \mathrm{g} / \mathrm{ml})$ through biofilm of $K$. pneumoniae B5055

\begin{tabular}{llll}
\hline Biofilm age (Days) & \multicolumn{2}{l}{ Inhibition zones $(\mathrm{mm})$ observed following penetration of gentamicin through disc placed on } & \multirow{2}{*}{$\%$ Retardation } \\
\cline { 2 - 3 } & Membrane with no biofilm & Membrane with colony biofilm & $26.66 \pm 0.17$ \\
3 & $15 \pm 0.06$ & $7 \pm 0.14$ & $53.33 \pm 0.18$ \\
5 & $15 \pm 0.08$ & $3 \pm 0.12$ & $80.06 \pm 0.15$ \\
7 & $15 \pm 0.12$ & $2 \pm 0.13$ & $86.66 \pm 0.20$ \\
\hline
\end{tabular}

The zone of growth inhibition observed on plates with discs having no biofilms was taken as $100 \%$ penetration and used to determine the percentage retardation of gentamicin through biofilms. Data is presented as mean \pm SD. The experiment was performed thrice in triplicates 

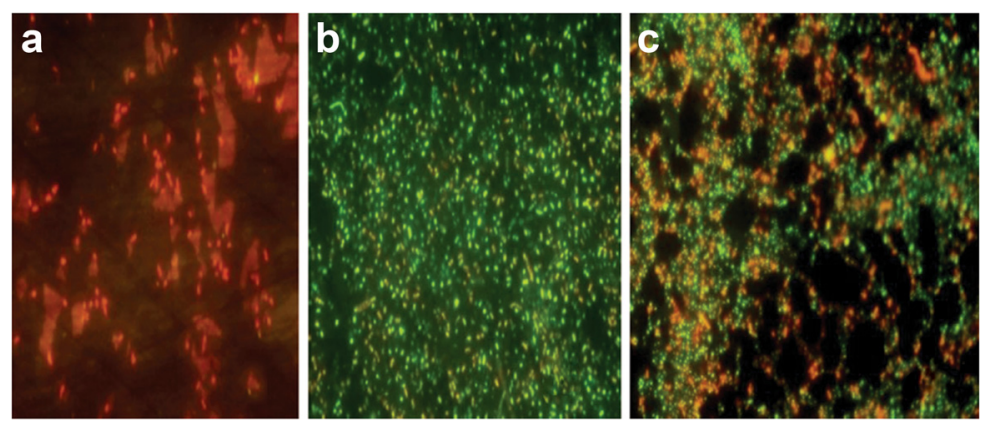

Fig. 2 Planktonic cells (a) Intact biofilm (b) and Disrupted biofilm (c) incubated for 6 h with gentamicin (10 $\mu \mathrm{g} / \mathrm{ml})$, stained with LIVE/DEAD

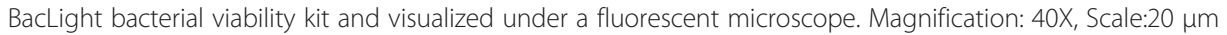

difference $(p>0.05)$ was observed in the ratio of red to blue fluorescence in phage depolymerase treated $(0.58 \mathrm{U})$ or untreated ( $0.34 \mathrm{U}), 7$ day old biofilm.

\section{Quantification of CPS in treated/untreated biofilms by ELLA}

ELLA involving measurement of peroxidase activity after binding of horse radish peroxidase (HRP) labeled lectin (concanavalin A) to sugar residues in polysaccharide was used for quantification of polysaccharide content in biofilm before and after treatment. A significant difference $(p<0.05)$ was observed in the average polysaccharide content $(\mu \mathrm{g} / \mathrm{ml})$ of untreated $(1.41 \pm 0.26)$ and bacterial depolymerase treated biofilm $(0.45 \pm 0.17)$ (Table 2). In contrast, no significant difference in average polysaccharide content was observed in untreated biofilm $(1.41 \pm 0.26)$ and biofilm treated with phage depolymerase $(0.90 \pm 0.25)$ (Table 2).

\section{Discussion}

CPS forms thick bundles of fibrillous structures that cover the entire surface of Klebsiella [7]. Because of the inherent tolerance of biofilm to antibiotics, there is a growing need for developing strategies for tackling biofilms $[29,30]$. The future of biofilm control lies in using microbes which produce antifouling enzymes [32]. Amylases, proteases, alginate lyases, dispersin, polyglutamic acid depolymerases have been widely accepted for disrupting the polysaccharides of $P$. aeruginosa, S. aureus, Bacillus spp. etc. [31]. Various commercially available proteases and polysaccharide degrading enzymes of bacterial and fungal origin, such as glucose oxidase (Novo Nordisk), Lactoperoxidase (Sigma), Pectinex Ultra SP (Novo Nordisk), Mutanase (Novo Nordisk), Dextranase (Novo Nordisk), Subtilisin A (Novo Nordisk) have been used against biofilm formed by Streptococcus mutans, Staphylococcus and Pseudomonas spp. in various environmental, clinical and industrial settings [32]. In our

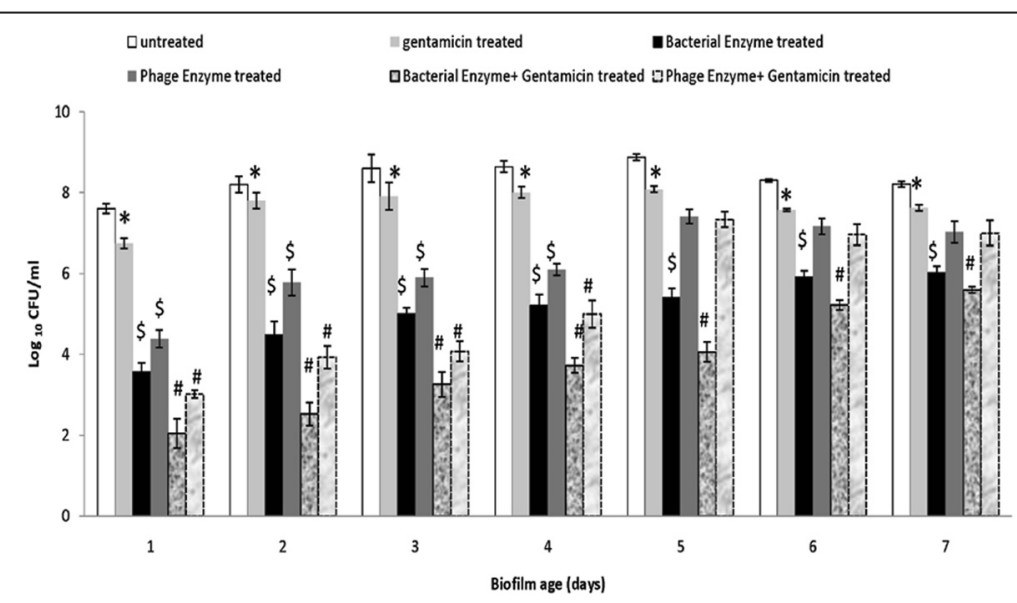

Fig. 3 Bacterial count $\left(\log _{10} \mathrm{CFU} / \mathrm{ml}\right)$ following treatment of intact biofilm of $K$. pneumoniae grown in microtiter plate, with gentamicin $(10 \mu \mathrm{\mu g} / \mathrm{ml}) / \mathrm{phage} /$ bacterial enzyme $(20 \mathrm{units} / \mathrm{ml})$ alone as well as in combination. The experiment was performed thrice in triplicate. Error bars $= \pm S D ; n=3\left[^{*} p>0.05\right.$ (gentamicin treated vs untreated), ${ }^{\$} p<0.05$ (bacterial/phage enzyme treated vs untreated), ${ }^{\#} p<0.05$ (bacterial enzyme + gentamicin/phage enzyme + gentamicin treated vs untreated)]. Denatured bacterial/phage depolymerase heated at $75^{\circ} \mathrm{C}$ for $10 \mathrm{~min}$ were used as controls for biofilm treatment. But no effect on CPS content was observed 


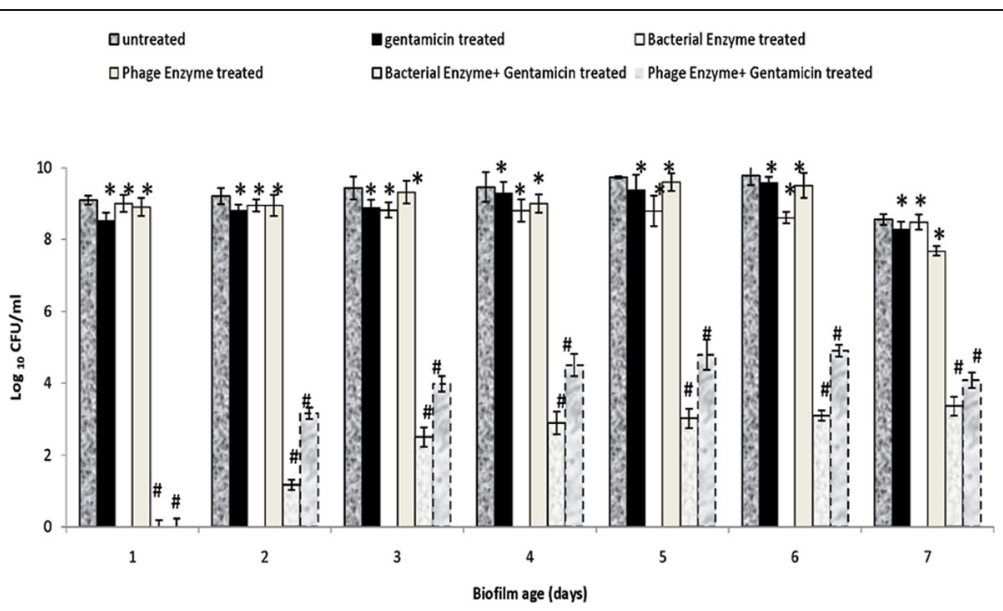

Fig. 4 Bacterial count ( $\left.\log _{10} \mathrm{CFU} / \mathrm{ml}\right)$ following treatment of disrupted biofilm of $K$. pneumoniae grown in microtiter plate, with gentamicin $(10 \mu \mathrm{g} / \mathrm{ml}) /$ phage/bacterial enzyme (20 units $/ \mathrm{ml})$ alone as well as in combination. The experiment was performed thrice in triplicate. Error bars $= \pm \mathrm{SD} ; n=3$. ${ }^{*} p>0.05$ (gentamicin/bacterial enzyme/phage enzyme treated vs untreated), ${ }^{*} p<0.05$ (bacterial enzyme + gentamicin/phage enzyme + gentamicin treated vs untreated)]. Denatured bacterial/phage depolymerase heated at $75^{\circ} \mathrm{C}$ for 10 min were used as controls for biofilm treatment. But no effect on CPS content was observed
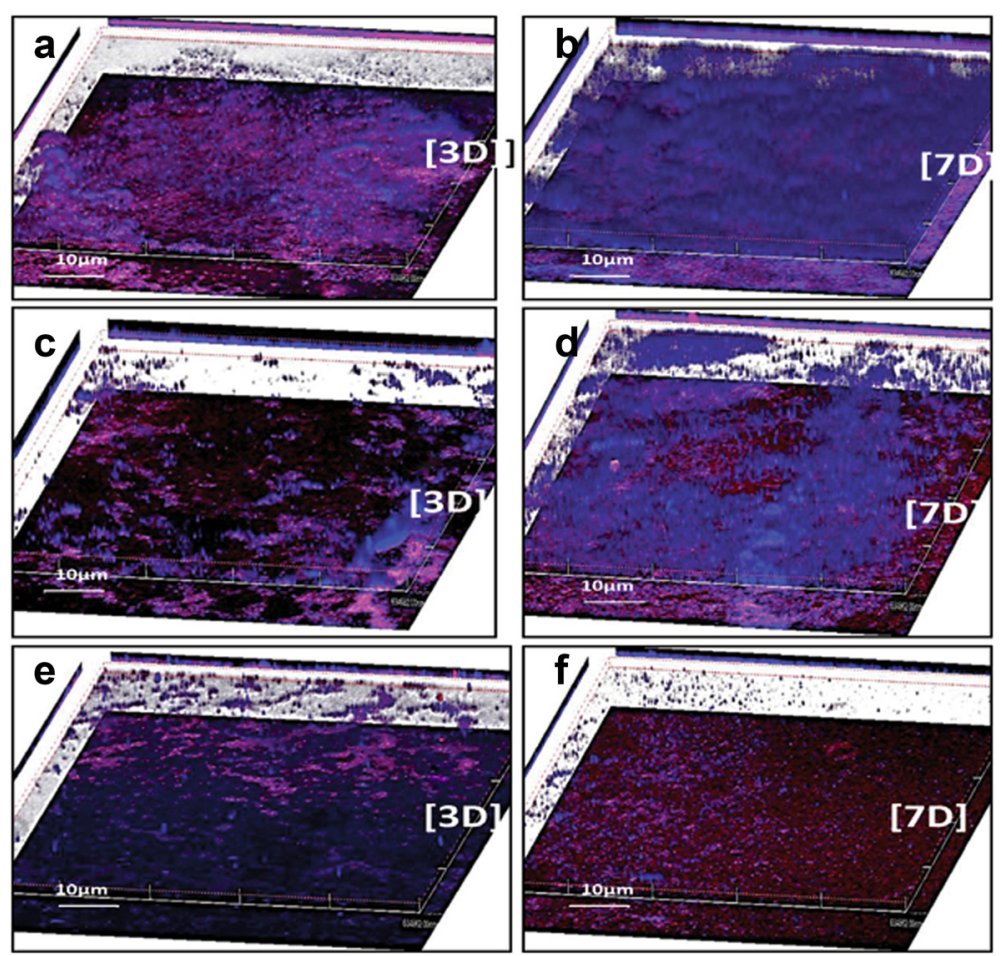

Fig. 5 3-D reconstruction of 3 and 7 day old biofilm after staining with calcofluor white and Syto 62 (a) 3 day untreated biofilm (b) 7 day untreated biofilm (c) 3 day biofilm treated with phage depolymerase (d) 7 day biofilm treated with phage depolymerase (e) 3 day biofilm treated with bacterial depolymerase (f) 7 day biofilm treated with bacterial depolymerase. Both the enzymes were used at 20 units/ml. (Magnification 200X). [3D]: 3 day old biofilm, [7D]: 7 day old biofilm, Scale: $10 \mu \mathrm{m}$ 
Table 2 CPS content $(\mu \mathrm{g} / \mathrm{ml})$ following treatment of $K$. pneumoniae biofilm of different days with phage/bacterial depolymerase (20 units/ml each)

\begin{tabular}{llll}
\hline Biofilm age & \multicolumn{2}{l}{ CPS content $(\mu \mathrm{g} / \mathrm{ml})$} & Bacterial enzyme treated $^{\#}$ \\
\cline { 2 - 4 } Days & Untreated & Phage enzyme treated $^{*}$ & $0.279 \pm 0.18$ \\
\hline 1 & $0.989 \pm 0.15$ & $0.639 \pm 0.22$ & $0.357 \pm 0.17$ \\
3 & $1.082 \pm 0.24$ & $0.846 \pm 0.36$ & $0.511 \pm 0.15$ \\
7 & $1.589 \pm 0.09$ & $0.978 \pm 0.24$ & $0.656 \pm 0.19$ \\
\hline
\end{tabular}

Data is presented as mean \pm SD $(n=3)$. [ ${ }^{*} p>0.05$ (average CPS content in phage depolymerase treated vs untreated biofilm), ${ }^{\#} p<0.05$ (average CPS content in bacterial depolymerase treated vs untreated biofilm)]. Denatured bacterial/phage depolymerase heated at $75{ }^{\circ} \mathrm{C}$ for $10 \mathrm{~min}$ were used as controls for biofilm treatment. But no effect on CPS content was observed

previous work, A. punctata derived capsule depolymerase has been shown to improve gentamicin efficacy during $K$. pneumoniae induced murine infection [19]. Thus, the potential of this depolymerase found to be extensively homologous to protein of unknown function from $A$. cavaie Ae398 [20], in mediating dispersal of biofilm formed by $K$. pneumoniae and improving gentamicin action was evaluated in this study.

Decapsulation of $K$. pneumoniae B5055 after treatment with $A$. punctata derived depolymerase is depicted in Fig. 1. Unlike antibacterial enzymes like endolysins, lysostaphin, lysozyme etc., depolymerase renders the bacterium susceptible to various antimicrobial agents due to digestion of outer CPS [33]. Aminoglycosides have been widely used for inhibiting/restricting the growth of members of enterobactericiae family. Thus, gentamicin was selected for use along with $A$. punctata derived depolymerase. It was used at $10 \mu \mathrm{g} / \mathrm{ml}$ throughout the study, as it is the clinical achievable concentration and optimal concentration approved by CLSI guidelines [34]. Resistance of intact biofilm to gentamicin may be due to the binding of positively charged aminoglycoside to negatively charged biofilm matrix. This has been reported by earlier workers, as tobramycin exhibited a limited or delayed penetration across biofilm of $P$. aeruginosa $[35,36]$. Thus, a significant decrease in the penetration of gentamicin with progression in biofilm age observed in this study, was possibly due to binding of gentamicin to the biofilm matrix. SubMIC levels of antibiotic thus reaching the biofilm interior may induce matrix synthesis and biofilm formation as reported for P. aeruginosa and Escherichia coli [29]. Repeated antibiotic dosing also offers no advantage in such cases as it causes saturation of binding sites rather than improving penetration across the biofilm $[37,38]$. Thus in this study, young and old biofilm of $K$. pneumoniae were treated with bacterial depolymerase. Although bacterial depolymerase when used alone was not directly bactericidal, a reduction in bacterial count of intact biofilm was observed. This might be due to enzyme catalyzed cleavage of the polysaccharide which caused a removal of the loosely bound, un-encapsulated cells. Earlier studies have reported the use of Dispersin B, 'a biofilm releasing enzyme' synergistically with various antimicrobials for the removal of biofilm formed by $S$. aureus, S. epidermidis and $E$. coli [39-41]. Therefore, when bacterial depolymerase was used along with gentamicin, degradation of negatively charged polysaccharide matrix enmeshing bacteria in a biofilm facilitated the transport of positively charged gentamicin across the biofilm. It ensured rapid killing of bacteria present in deeper layers and prevented exposure of bacteria to sub-MIC concentrations of antibiotic as has been reported earlier [42]. Increase in biofilm matrix with an increase in biofilm age which contributed towards inability of gentamicin to penetrate was confirmed by viewing the biofilms by CLSM. The degradation of polysaccharide after treatment with bacterial depolymerase which led to dispersal of loosely bound cells and killing of deep seated bacterial cells by gentamicin was also confirmed through CLSM and ELLA.

Biofilm disruption occurs during its dispersal, due to fluid infusion through them or due to removal of implanted biomaterials like catheters, stents, cardiac pacemakers, endotracheal tubes, joint prostheses, peritoneal dialysis catheters, cerebrospinal fluid shunts etc. Shed bacteria can enter into circulation and cause infections like pneumonia, septicemia and secondary infections especially in immunocompromised individuals [43]. They can also readhere and initiate biofilm formation elsewhere. Stewart and Costerton [44] have reported that antibiotics might kill the free floating bacteria shed from a biofilm. Contrasting results were obtained in our study whereby significant recalcitrance of disrupted biofilm cells to gentamicin was observed. This might be due to the presence of disrupted biofilm cells in clusters. Inability of vancomycin and linezolid to combat disrupted biofilm of methicillin resistant $S$. aureus (MRSA) and methicillin susceptible S. aureus (MSSA) at concentrations 1000 times higher than their MICs has also been reported by El-Azizi et al. [27]. Bacterial depolymerase when used in combination with gentamicin caused significant reduction in the count of disrupted cells due to their release from cluster.

Throughout this study, a previously characterized phage borne depolymerase capable of degrading the CPS of $K$. pneumoniae B5055 was used alongwith bacterial 
depolymerase for biofilm treatment. Even though both

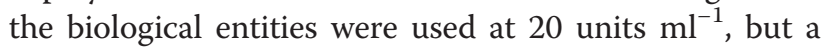
better efficacy of bacterial depolymerase over its phage counterpart was visibly clear. During biofilm treatment, phage depolymerase caused ineffective dissolution of polysaccharide especially in older biofilm. Thus, reduction in bacterial count in biofilms treated with phage depolymerase was $\sim 2 \log$ less in comparison to biofilm treated with bacterial depolymerase. Similarly, polysaccharide content after bacterial depolymerase treatment was significantly less in comparison to that observed in biofilm after phage depolymerase treatment. Reason for this anomaly lies in the enzyme kinetics of both the enzymes. Interestingly, a high affinity of the bacterial depolymerase towards its substrate (indicated by its lower $\mathrm{K}_{\mathrm{m}}$ value $=89.88 \mu \mathrm{M})$ over that of phage depolymerase $\left(K_{m}\right.$ value $=150 \mu \mathrm{M})$ and its higher efficiency in liberating reducing sugars [indicated by a higher turnover number $\left(\mathrm{k}_{\mathrm{cat}}=285 \mathrm{~s}^{-1}\right)$ ] over phage depolymerase $\left(\mathrm{k}_{\mathrm{cat}}=107 \mathrm{~s}^{-1}\right)$ was possibly a reason for its higher efficacy than the phage depolymerase (Kinetics of phage depolymerase: Additional file 1: Table S1). Jun et al. [45] have reported a phage endolysin 'SAL-1', to possess better efficacy than endolysin 'LysK' due to alterations in amino acid residues in catalytic domain. This is the first comparative study on two biological entities capable of degrading the CPS of a gram negative bacterium. The enzyme of bacterial origin was found to show better efficacy over its phage derived counterpart. It is suggested that these biological entities should be further explored for valuable insights into this interesting phenomena.

\section{Conclusion}

In recent times, antimicrobial drug development is increasingly lagging behind the evolution of antibiotic resistance. Considering the degree of virulence possessed by K1 or K2 CPS containing $K$. pneumoniae strains [46] newer antibiofilm therapeutic paradigms are required. The potential of phage borne depolymerase in degrading the biofilm polysaccharide and allowing the phage or other antimicrobials to reach the bacterial cell surface has been widely demonstrated [47-50]. But, obtaining large amounts of phage depolymerases from phage lysates is difficult [33, 51, 52]. Moreover, chances of isolating a natural phage that is specific for a bacteria to be targeted and having the ability to express a relevant polysaccharide degrading enzyme are low [53]. A strategy of engineering bacteria specific phages to express effective polysaccharide degrading enzymes has been looked upon [34]. Use of genetically modified phages which help in overcoming antibiotic resistance [54] or which efficiently kill but simultaneously minimize endotoxin release from the pathogen $[55,56]$ is also being tried. But, instead of adopting a tedious approach, an enzyme derived from naturally occurring unrelated bacterial genera was used in this study. Such enzymes do not allow generation of resistant mutants, do not involve bacterial lysis and subsequent release of proinflammatory mediators, do not require actively growing cells to exert their action and serve as adjuncts to improve antibiotic action. Promising results obtained with bacterial depolymerase and its better efficacy in comparison to phage depolymerase warrant its further evaluation in in vivo studies so that it can be readily incorporated in prophylactic/therapeutic regimes.

\section{Additional file}

\begin{abstract}
Additional file 1: Characteristics of bacterial and phage
depolymerase Figure S1. Determination of optimum temperature (a) and temperature stability (b) of bacterial depolymerase. Determination of optimum pH (c) and pH stability (d) of bacterial depolymerase. Figure S2. Line-weaver Burk plot depicting the kinetics of bacterial depolymerase. $\mathrm{K}_{\mathrm{m}}=89.88 \mu \mathrm{M}, \mathrm{V}_{\text {max }}=43.35 \mu \mathrm{mole} / \mathrm{min}, \mathrm{K}_{\text {cat }}=285 \mathrm{~s}^{-1}, \mathrm{~K}_{\mathrm{cat}} / \mathrm{K}_{\mathrm{m}}=3.17 \mathrm{~s}^{-1} \cdot \mu \mathrm{M}^{-1}$. Figure S3. Determination of optimum temperature (a) and temperature stability (b) of phage 'KPO1K2' derived depolymerase. Determination of optimum $\mathrm{pH}$ (c) and pH stability (d) of phage 'KPO1K2' derived depolymerase. Table S1. Kinetics of phage depolymerase.
\end{abstract}

\section{Competing interests}

The authors declare that they have no competing interests.

\section{Authors' contributions}

Conceived and designed the experiments: SB, SC, KH; Performed the experiments: SB; Analyzed the data: SB, SC; Wrote the paper: SB, SC, KH. All authors read and approved the final manuscript.

\section{Acknowledgment}

We thank Dr. Vivekanand Jha and Ms. Harmandeep Kaur, Department of Stem cell Research, PGIMER, Chandigarh, India for their help with the CLSM. $\mathrm{S}$. Bansal is a recipient of a Senior Research fellowship from Council for Scientific and Industrial Research (CSIR), India.

\section{Funding}

This work was not supported by any external funding source.

Received: 1 August 2014 Accepted: 28 May 2015

Published online: 11 June 2015

\section{References}

1. Flemming HC, Wingender J. The biofilm matrix. Nat Rev Microbiol. 2010:8:623-33.

2. Moscoso M, García E, López R. Pneumococcal biofilms. Int Microbiol. 2009;12:77-85

3. Rezaei E, Safari H, Naderinasab M, Aliakbarian H. Common pathogens in burn wound and changes in their drug sensitivity. Burns. 2011:37:805-7.

4. Sahly H, Podschun R. Clinical, bacteriological, and serological aspects of Klebsiella infections and their spondylarthropathic sequelae. Clin Diagn Lab Immunol. 1997;4:393-9.

5. Lai YC, Peng HL, Chang HY. RmpA2, an activator of capsule biosynthesis in Klebsiella pneumoniae CG43, regulates K2 cps gene expression at the transcriptional level. J Bacteriol. 2003;185:788-800.

6. Murphy CN, Clegg S. Klebsiella pneumoniae and type 3 fimbriae: nosocomial infection, regulation and biofilm formation. Future Microbiol. 2012;7:991-1002.

7. Podschun R, Ullmann U. Klebsiella spp. as nosocomial pathogens: epidemiology, taxonomy, typing methods and pathogenicity factors. Clin Microbiol Rev. 1998;11:589-603.

8. Cano V, Moranta D, Llobet-Brossa E, Bengoechea JA, Garmendia J. Klebsiella pneumoniae triggers a cytotoxic effect on airway epithelial cells. BMC Microbiol. 2009;9:156. 
9. Russo TA, Gill SR. Draft genome sequence of the hypervirulent Klebsiella pneumoniae strain hvKP1, isolated in Buffalo, New York. Genome Announce. 2013;1:e0006513.

10. Stewart PS. Theoretical aspects of antibiotic diffusion into microbial biofilms. Antimicrob Agents Chemother. 1996;40:2517-22.

11. Hughes KA, Sutherland IW, Clark J, Jones M. Bacteriophage and associated polysaccharide depolymerases novel tools for study of bacterial biofilms. J Appl Microbiol. 1998:85:583-90.

12. Høiby N, Bjarnsholta T, Givskov M, Molinc S, Ciofu O. Antibiotic resistance of bacterial biofilms. Int J Antimic Agents. 2010;35:322-32.

13. Llobet $E$, Tomas JM, Bengoechea JA. Capsule polysaccharide is a bacterial decoy for antimicrobial peptides. Microbiology. 2008;154:3877-86.

14. Anderl JN, Zahller J, Roe F, Stewart PS. Role of nutrient limitation and stationary-phase existence in Klebsiella pneumoniae biofilm resistance to ampicillin and ciprofloxacin. Antimicrob Agents Chemother. 2003;47:1251-6.

15. Donlan RM. Biofilm elimination on intravascular catheters: important considerations for the infectious disease practitioner. Clin Infect Dis. 2011;52:1038-45.

16. Thallinger B, Prasetyo EN, Nyanhongo GS, Guebitz GM. Antimicrobial enzymes: an emerging strategy to fight microbes and microbial biofilms. J Biotechnol. 2013:8:97-109.

17. Azeredo J, Sutherland IW. The use of phages for the removal of infectious biofilms. Curr Pharmac Biotechnol. 2008;9:261-6.

18. Pastagia M, Euler C, Chahales P, Fuentes-Duculan J, Krueger JG, Fischetti VA. A novel chimeric lysin shows superiority to mupirocin for skin decolonization of methicillin resistant and sensitive Staphylococcus aureus strains. Antimicrob Agents Chemother. 2011;55:738-44.

19. Bansal S, Harjai K, Chhibber S. Depolymerase improves gentamicin efficacy during Klebsiella pneumoniae induced murine infection. BMC Infect Dis 2014; 14:456

20. Bansal S, Harjai K, Soni SK, Chhibber S. Aeromonas punctata derived depolymerase that disrupts the integrity of Klebsiella pneumoniae capsule: Optimization of depolymerase production. J Basic Microbiol. 2013;53:1-10.

21. Hanlon GW, Denyer SP, Olliff CJ, Ibrahim LJ. Reduction in exopolysaccharide viscosity as an aid to bacteriophage penetration through Pseudomonas aeruginosa biofilms. Appl Environ Microbiol. 2001;67:2746-53.

22. Miller GL. Use of dinitrosalicylic acid reagent for determination of reducing sugar. Anal Chem. 1959;31:426-8.

23. Verma V, Harjai K, Chhibber S. Characterization of a T7-like lytic bacteriophage of Klebsiella pneumoniae B5055: a potential therapeutic agent. Curr Microbiol. 2009;59:274-81.

24. Reiger D, Molbert EF, Stirm S. Escherichia coli capsule bacteriophages III. Fragments of bacteriophage 29. J Virol. 1975;15:964-75.

25. Anderl JN, Franklin MJ, Stewarti PR. Role of antibiotic penetration limitation in Klebsiella pneumoniae biofilm resistance to ampicillin and ciprofloxacin. Antimicrob Agents Chemother. 2000;44:1818-24.

26. Bedi MS, Verma V, Chhibber S. Amoxicillin and specific bacteriophage can be used together for eradication of biofilm of Klebsiella pneumoniae B5055. World J Microbiol Biotechnol. 2009;25:1145-51.

27. El-Azizi M, Rao S, Kanchanapoom T, Khardori N. In vitro activity of vancomycin, quinupristin/dalfopristin and linezolid against intact and disrupted biofilms of Staphylococci. Ann Clin Microbiol Antimicrob. 2005:4:21-9.

28. Strathmann M, Wingender J, Flemming HC. Application of fluorescently labeled lectins for the visualization and biochemical characterization of polysaccharides in biofilms of Pseudomonas aeruginosa. J Microbiol Meth. 2002:50:237-48.

29. Hoffman LR, D'Argenio DA, MacCoss MJ, Zhang Z, Jones RA, Miller SI. Aminoglycoside antibiotics induce bacterial biofilm formation. Nature. 2005;436:1171-5.

30. Saha R, Saha N, Donofrio RS, Bestervelt LL. Microbial siderophores: a mini review. J Basic Microbiol. 2013:53:303-17.

31. Leslie A. Preventing biofilm formation using microbes and their enzymes. MMG 445 Basic Biotechnol. 2011;7:6-11.

32. Johansen C, Falholt P, Gram L. Enzymatic removal and disinfection of bacterial biofilms. Appl Environ Microbiol. 1997;63:3724-8.

33. Lu TK, Collins JJ. Dispersing biofilms with engineered enzymatic bacteriophage. Proc Natl Acad Sci. 2007:104:11197-202.

34. Lewis K. Riddle of biofilm resistance. Antimicrob Agents Chemother. 2001:45:999-1007.
35. Hunt BE, Weber A, Berger A, Ramsey B, Smith AL. Macromolecular mechanisms of sputum inhibition of tobramycin activity. Antimicrob Agents Chemother. 1995;39:34-9.

36. Hatch RA, Schiller NL. Alginate lyase promotes diffusion of aminoglycosides through the extracellular polysaccharide of mucoid Pseudomonas aeruginosa. Antimicrob Agents Chemother. 1998:42:974-7.

37. Anwar H, Strap JL, Costerton JW. Establishment of aging biofilms: possible mechanism of bacterial resistance to antimicrobial therapy. Antimicrob Agents Chemother. 1992;36:1347-51.

38. Wood LF, Leech AJ, Ohman DE. Cell wall-inhibitory antibiotics activate the alginate biosynthesis operon in Pseudomonas aeruginosa: roles of sigma (AlgT) and the AlgW and Prc proteases. Mol Microbiol. 2006;62:412-26.

39. Presterl E, Grisold AJ, Reichmann S, Hirschl AM, Georgopoulos A, Graninger W. Viridans Streptococci in endocarditis and neutropenic sepsis: biofilm formation and effects of antibiotics. J Antimicrob Chemother. 2005;55:45-50.

40. Izano EA, Sadovskaya I, Vinogradov E, Mulks MH, Velliyagounder K, Ragunath $\mathrm{C}$, et al. Poly-N-acetylglucosamine mediates biofilm formation and antibiotic resistance in Actinobacillus pleuropneumoniae. Microb Pathog. 2007;43:1-9.

41. Izano EA, Wang H, Ragunath C, Ramasubbu N, Kaplan JB. Detachment and killing of Aggregatibacter actinomycetemcomitans biofilms by dispersin B and SDS. J Dent Res. 2007:86:618-22.

42. Pamp SJ, Gjermansen M, Tolker-Nielsen T. The biofilm matrix-A sticky framework. In: Kjelleberg S, Norfolk GM, editors. The Biofilm Mode of Life. Horizon Bioscience. 2007. p. 37-69.

43. Ymele-Leki P, Ross JM. Erosion from Staphylococcus aureus biofilms grown under physiologically relevant fluid shear forces yields bacterial cells with reduced avidity to collagen. Appl Environ Microbiol. 2007;73:1834-41.

44. Stewart PS, Costerton JW. Antibiotic resistance of bacteria in biofilms. Lancet. 2001;358:135-8.

45. Jun SY, Jung GM, Son JS, Yoon SJ, Choi YJ, Kang SH. Comparison of the antibacterial properties of phage endolysins SAL-1 and LysK. Antimicrob Agents Chemother. 2011;55:1764-7.

46. Mizuta K, Ohta M, Mori M, Hasegawa T, Nakashima I, Kato N. Virulence for mice of Klebsiella strains belonging to the $\mathrm{O} 1$ group: relationship to their capsular (K) types. Infect Immun. 1983:40:56-61.

47. Mushtaq N, Redpath MB, Luzio JP, Taylor PW. Prevention and cure of systemic Escherichia coli K1 infection by modification of the bacterial phenotype. Antimicrob Agents Chemother. 2004;48:1503-8.

48. Scorpio A, Tobery SA, Ribot WJ, Friedlander AM. Treatment of experimental anthrax with recombinant capsule depolymerase. Antimicrob Agents Chemother. 2008:13:1014-20.

49. Hsu CR, Lin TL, Pan YJ, Hsieh PF, Wang JT. Isolation of a bacteriophage specific for a new capsular type of Klebsiella pneumoniae and characterization of its polysaccharide depolymerase. Plos One. 2013:8:e70092

50. Pleteneva EA, Bourkaltseva MV, Shaburova OV, Krylov SV, Pechnikova EV, Sokolova OS, et al. TL, the new bacteriophage of Pseudomonas aeruginosa and its application for the search of halo producing bacteriophages. Rus J Gen. 2011:47:1-5.

51. Vandenbergh PA: Bacteria for expressing a polysaccharide depolymerase containing a novel recombinant plasmid. 1989, US 4822740 A.

52. Tomlinson S, Taylor PW. Neuraminidase associated with coliphage E that specifically depolymerizes the Escherichia coli K1 capsular polysaccharide. J Virol. 1985;55:374-8.

53. Projan S. Phage-inspired antibiotics? Nat Biotechnol. 2004;22:167-8.

54. Lu TK, Collins JJ. Engineered bacteriophage targeting gene networks as adjuvants for antibiotic therapy. Proc Natl Acad Sci. 2009;106:4629-34.

55. Hagens S, Bläsi U. Genetically modified filamentous phage as bactericidal agents: a pilot study. Lett Appl Microbiol. 2003;37:318-23.

56. Hagens S, Habel A, Ahsen U, Gabain A, Bläsi U. Therapy of experimental Pseudomonas infections with a nonreplicating genetically modified phage. Antimicrob Agents Chemother. 2004;48:3817-22.

57. Schneider CA, Rasband WS, Eliceiri KW. NIH Image to ImageJ: 25 years of image analysis. Nat Methods. 2012;9:671-5. 